\title{
Логика абсурда в Повести о ссоре Гоголя
}

\section{The Logic of the Absurd in Gogol's The Story about Quarrel}

\author{
Владислав Шаевич Кривонос \\ (Самара, Россия)
}

\section{Абстракт:}

В статье изучаются особенности логики абсурда в Повести о ссоре Гоголя. Рассматриваются функции хаоса в сюжете повести. Раскрываются причины трансформации пространства Миргорода в хаос, служащий формой выражения абсурда. Показаны формы наступления на город сил хаоса и разрушения границ между хаосом и человеком. Демонстрируются способы воссоздание в повести атмосферы первотворения пространства Миргорода и принципы иронического переосмысления мифов творения. Подчеркнута важная связь мифического прошлого и мифологизированного настоящего в истории Миргорода. Испорченное ружье, ставшее причиной ссоры героев, рассматривается как символическая вещь, которая имеет прямое отношение к времени первотворения. Отмечено сходство героев повести с простаками и глупцами из анекдотической сказки. Раскрывая алогичный характер сюжетных событий и действий героев, автор осмысляет абсурд как сущность изображенного Гоголем мира.

\section{Ключевые слова:}

Гоголь; мир; пространство; ссора; хаос; алогизм; абсурд

\section{Abstract:}

The author studies the features of the logic of the absurd in Gogol's The Story about quarrel. The functions of chaos in the plot of the story are considered. The reasons for the transformation of the space of Mirgorod into chaos, which serves as a form 
of expression of the absurd, are revealed. The forms of attack on the city of chaos forces and the destruction of borders between chaos and man are shown. The ways to recreate in the story the atmosphere of the creation of the space of Mirgorod and the principles of ironic rethinking of creation myths are demonstrated. The important connection between the mythical past and the mythologized present in the history of Mirgorod is underlined. The spoiled gun, which caused of the quarrels of the heroes, is considered as a symbolic thing that is directly related to the time of creation. The similarity of the heroes of the story with simpletons and fools from an anecdotal tale is noted. Revealing the illogical nature of the plot events and actions of the heroes, the author interprets the absurd as the essence of the world depicted by Gogol.

\section{Key words:}

Gogol'; world; space; quarrel; chaos; alogism; absurd

Сюжетным и пространственным выражением абсурда в «Повести о том, как поссорился Иван Иванович с Иваном Никифоровичем» служит охвативший Миргород хаос, явившийся следствием ссоры Ивана Ивановича и Ивана Никифоровича. В результате не только разрушается привычное устройство миргородской жизни, но и ход событий становится все более непредсказуемым, приводящим к окончательному разрыву дружеских связей и необратимому распаду казавшегося единым мира. Венчающие повествование символические образы человеческой разобщенности и бессмысленного раздора, порожденные видом пустой церкви и обликом неузнаваемо изменившихся героев, сочетаясь с картиной «серой массы грязи» и дождя, лившего «ливмя» ${ }^{1}$, вызывают ассоциации с характеризующими хаос представлениями о всеобщем разъединении, водном потопе и внезапно раскрывшейся бездне.

Важным источником хаоса и очевидным признаком его наступления являются действия рассорившихся приятелей, связанные с нарушением ими социальных и моральных запретов и норм. Иван Никифорович «с дьявольской скоростью» выстраивает против соседа, захватив часть его земли, «гусиный хлев, как будто с особенным намерением усугубить оскорбление» ${ }^{2}$. А Иван Иванович ночью подпиливает столбы, на которых этот хлев держался, так что здание «рухнуло с треском» ${ }^{3}$. После чего, испугавшись, что «ненавистный сосед» в отместку «подожжет дом его», побежал «подать на него прошение

1 GOGOL', N. V.: Polnoje sobranije sočinenij: V 14 t. T. II. [Moskva-Leningrad]: AN SSSR, 1937, s. 276.

2 Там же, с. 242.

3 Там же, с. 243. 
в миргородский поветовый суд» ${ }^{4}$. Следом в тот же суд наведался Иван Никифорович с жалобой на «разбойника», требуя препроводить того «тюрьму или государственный острог» ${ }^{5}$.

В миргородском пространстве, которое, как обнаруживается, способно легко трансформироваться в хаос, захватывающий чувства и мысли героев, граница между человеком и хаосом становится размытой и проницаемой, как в соответствующих мифопоэтических описаниях. Ненадежной оказывается граница и между хаосом и принадлежащим человеку животным; речь идет о бурой свинье, которую Иван Иванович предлагал поменять на ружье, но получил отказ: «Это таки ружье - вещь известная; а то чорт знает что такое: свинья» ${ }^{6}$. Неожиданно появившись в суде, хавронья, «к удивлению присутствовавших», схватила и похитила «прошение Ивана Никифоровича» ${ }^{7}$. Свинья ведет себя так, как если бы она обиделась на данное ей прозвище и решила доказать своим поступком, что она тоже вещь известная.

Наступление сил хаоса несет в себе угрозу существованию Миргорода, наделенного чертами мифологизированного пространства. Ср.: «Что за асамблею дал городничий! Позвольте, я перечту всех, которые были там: Тарас Тарасович, Евпл Акинфович, Евтихий Евтихиевич, Иван Иванович, не тот Иван Иванович, а другой, Савва Гаврилович, наш Иван Иванович, Елевферий Елевфериевич, Макар Назарьевич, Фома Григорьевич...» ${ }^{8}$. Почти полный перечень присутствующих призван описать и объяснить устройство миргородского пространства, являющегося для его обитателей своей территорией, на которой проживают только свои, все те, кто имеет какое-либо отношение к истории сотворения их общего мира. Мифология Миргорода, неотделимая от его космогонии, санкционирует подобное устройство.

Особое значение приобретают здесь пространственные реалии, отсылающие к мифическому прошлому и соединяющие его с мифологизированным настоящим. Такова воспетая рассказчиком лужа: «Если будете подходить к площади, то, верно, на время остановитесь полюбоваться видом: на ней находится лужа, удивительная лужа! единственная, какую только вам удавалось когда видеть! Она занимает почти всю площадь. Прекрасная лужа! Домы и домики, которые издали можно принять за копны сена, обступивши вокруг,

$\begin{array}{ll}4 & \text { Там же. } \\ 5 & \text { Там же, с. } 254 . \\ 6 & \text { Там же, с. } 235 . \\ 7 & \text { Там же, с. } 255 . \\ 8 & \text { Там же, с. } 264 .\end{array}$


дивятся красоте ее» ${ }^{9}$. Лужа оказывается не только значимой частью городского пейзажа, но и важнейшим знаком общего для рассказчика и персонажей мира; она играет здесь роль пародийного сакрального центра.

Пространство Миргорода, где мифологические реалии лишены сакрального значения, а священное время космогонии выродилось в рутинный ритуал, выстроено горизонтально и не знает вертикального измерения; персонажи предаются своим обыденным занятиям и развлечениям и погружены в сугубо бытовые заботы. Так, Иван Иванович «очень любит дыни», которые мифологически означивают его существование: он «сам разрежет, соберет семена в особую бумажку, и начнет кушать», а потом «велит Гапке принести чернильницу и сам, собственною рукою, сделает надпись над бумажкою с семенами: сия дыня съедена такого-то числа» ${ }^{10}$. Повторяющееся событие, будучи пародийной имитацией перводействия, призвано приобщить Ивана Ивановича к начальному времени, которое в акте еды символически восстанавливается.

Еда как способ воспроизведения одного из важнейших перводействий, символизирующих мифическое прошлое, позволяет поддерживать установленный некогда и поныне сохраняющийся порядок. Отсюда особая значимость ритуальной роли еды. Недаром рассказчик впадает в патетику, понятную, когда речь заходит о еде, всем приобщенным к этому космогоническому акту: «Не стану описывать кушаньев, какие были за столом! Ничего не упомяну ни о мнишках в сметане, ни об утрибке, которую подавали к борщу, ни об индейке с сливами и изюмом... Не стану говорить об этих кушаньях потому, что мне гораздо более нравится есть их, нежели распространяться об них в разговорах» ${ }^{11}$. Перечисление кушаньев, хоть рассказчик деланно отказывается от полного их описания, заново воссоздает атмосферу первотворения общего для персонажей пространства.

В «Повести о том...», где повествование организовано в духе мифологического описания мира, иронически переосмыслены мифы творения. Открывается повествование знаменательным откровением рассказчика, касающимся бекеши Ивана Ивановича: «Он сшил ее тогда еще, когда Агафия Федосеевна не ездила в Киев. Вы знаете Агафию Федосеевну? та самая, что откусила ухо у заседателя» ${ }^{12}$. Происхождение бекеши как одного из первоэлементов сотворенного мира отнесено к мифическому прошлому, как отнесен к этому

\footnotetext{
9 Там же, с. 244.

10 Там же, с. 224.

11 Там же, с. 271.

12 Там же, с. 223.
} 
прошлому и поступок Агафии Федосеевны, приобретающий космогоническое значение.

Мир, в истории первотворения которого отдельно упоминается откушенное ухо, изначально чреват был хаотизацией; приятели, к одному из которых mа самая Агафии Федосеевны «ездила и проживала по целым неделям» ${ }^{13}$, просто не могли не поссориться, даром что их «сам чорт связал веревочкой» ${ }^{14}$. Именно ее вмешательство, не позволив погасить только разгоравшийся «огонь вражды» ${ }^{15}$, сначала привело к тому, «...что Иван Никифорович и слышать не хотел об Иване Ивановиче» ${ }^{16}$. А затем, когда обнаружилось, что свинья Ивана Ивановича утащила из суда прошение, она уговорила Ивана Никифоровича затеять новую судебную тяжбу, найдя где-то для сочинения жалобы «совершенную приказную чернильницу» ${ }^{17}$. Так то самое ухо связалось в истории ссоры с ружьем, послужившим ее причиной.

Ружье Ивана Никифоровича наделено функцией уникального первопредмета, имеющего непосредственное отношение к времени первотворения: «Таких ружьев теперь не сыщете нигде. Я еще как собирался в милицию, купил его у турчина» ${ }^{18}$. Для героя это не только «вещь необходимая» в случае защиты, если «нападут на дом разбойники» ${ }^{19}$, но и «вещь благородная» ${ }^{20}$. Она несет в себе память о мифическом прошлом, почему предложение Ивана Ивановича поменять ружье на свинью так возмущает Ивана Никифоровича; если б не дружба, то он, по его собственному признанию, сразу «...бы мог это принять в обидную для себя сторону» ${ }^{21}$. Эта необходимая и благородная вещь включена в мифологию сотворения мира, где он обитает и который считает своим, тогда как свинья, обладающая, согласно мифологическим представлениям, не чуждым герою, для которого она черт знает что такое, свойствами демонического существа, принадлежит, подобно разбойникам, к сфере хаоса.

Роль ружья состоит в том, чтобы, напоминая о начальном времени, дать представление о присущем некогда герою мужском образе жизни; это символическая вещь, характеризующая занятия, к которым склонен был Иван

\footnotetext{
13 Там же, с. 240.

14 Там же, с. 226.

15 Там же, с. 240.

16 Там же, с. 241.

17 Там же, с. 261.

18 Там же, с. 234.

19 Там же.

20 Там же, с. 235.

21 Там же.
} 
Никифорович, когда «собирался в милицию» ${ }^{22}$ и не попал еще под власть Агафии Федосеевны, всегда бравшей над ним «верх» ${ }^{23}$. Теперь же ружье, у которого «замок испорчен», ржавеет и «стоит в коморе» ${ }^{24}$; им можно разве что, для чего его и хочет выменять Иван Иванович, «позабавиться» ${ }^{25}$. Торг, который ведут приятели, показывает, что человек и вещь поменялись местами: не человек обладает нужной ему вещью, чтобы использовать ее по назначению, а вещь, пришедшая в негодность, почему обладание ею становится бессмысленным, сама обладает человеком, что предопределяет абсурдный характер ссоры.

Среди старых и пришедших в негодность вещей, которые развешивает старуха во дворе Ивана Никифоровича, Ивану Ивановичу бросаются в глаза «шпага, походившая на шпиц, торчавший в воздухе», и «старинное седло с оборванными стременами, с истертыми кожаными чехлами для пистолетов» ${ }^{26}$. Это тоже, подобно ружью, атрибуты воина, утратившие свое назначение; их нынешнее состояние указывает на изменившийся образ жизни героя, неподвижно лежавшего «весь день на крыльце» ${ }^{27}$, что делает его подобным «залежалому платью» ${ }^{28}$, покоящемуся в кладовой. Ср. показательный ход мысли Ивана Ивановича, наблюдавшего за происходящим, и последующий комментарий рассказчика: «„Вот глупая баба!“ подумал Иван Иванович: „она еще вытащит и самого Ивана Никифоровича проветривать!“ И точно: Иван Иванович не совсем ошибся в своей догадке. Минут через пять воздвигнулись нанковые шаровары Ивана Никифоровича и заняли собою почти половину двора» ${ }^{29}$.

Суждение рассказчика (не совсем ошибся) выглядит весьма симптоматичным не только потому, что вещь словно вытесняет из его кругозора человека. Граница между человеком и вещью не объединяет их, как прежде, в мифологические времена, но лишь разъединяет, что подчеркивает изменившийся статус и самой вещи, существование которой лишено какого-либо смысла, и человека, этой бессмыслицы не замечающего. Ведь его собственное поведение, что демонстрирует повод для ссоры между приятелями, граничит с абсурдом.

22 Там же, с. 234 .

23 Там же, с. 241.

24 Там же, с. 234.

25 Там же, с. 231.

26 Там же, с. 229.

27 Там же, с. 226.

28 Там же, с. 228.

29 Там же, с. 292-230. 
Несостоявшаяся мена ружья на свинью заканчивается обменом сравнениями: Иван Никифорович разносился «с своим ружьем, как дурень с писаною торбою», так как оно не заслуживает излишнего внимания и чрезмерных похвал, а Иван Иванович, сильно размахавшийся руками, «настоящий гусак» ${ }^{30}$, поскольку действиями своими напоминает гусака. Просторечное выражение, к которому прибегнул Иван Иванович, не вызывает такой острой реакции, как именование его самого гусаком. Хоть Иван Никифорович и пояснил, что имеет в виду всего лишь внешнее сходство, Иван Иванович посчитал, будто приятель, «позабыв и приличие и уважение к чину и фамилии человека», намеренно решил «обесчестить»его «таким поносным именем» ${ }^{31}$.

Приняв сравнение за бранное имя, Иван Никифорович в жалобе в поветовый суд приводит в качестве доказательства своего дворянского происхождения запись «в метрической книге», так как гусак «не может быть записан в метрической книге, ибо гусак есть не человек, а птица» ${ }^{32}$. Для героя дело не только в недопустимом изменении его социального статуса и не в самом по себе слове, показавшемся ему оскорбительным, что, как предполагает рассказчик, не исключало примирения «на другой же бы день» ${ }^{33}$, если бы не Агафия Федосеевна, но в воображаемом превращении его посредством именования из человека в птицу.

Гусак, в соответствии с логикой мифологического мышления, которой придерживается Иван Иванович, выступает как персонифицирующее его имя собственное. То есть Иван Никифорович, назвав приятеля поносным именем, не просто уподобил его гусаку, но и отождествил с гусаком, словно тот и есть гусак. Архаическое сознание, как известно, наделяло слово такой магической силой, будто оно действительно могло превратить человека в животное. Отмеченная логика в ситуации, побуждающей Ивана Ивановича следовать ей чуть ли не буквально (отсюда и ссылка на запись в метрической книге), представляется абсурдной, поскольку основана на абсурдном умозаключении; между тем именование гусаком он воспринимает именно как потенциальную метаморфозу.

Рассказчик в «Повести о том...», будучи близким или хорошим знакомым обитателей Миргорода, представляет себя как свидетеля и наблюдателя описываемых событий. Его идентичность миру, происходящее в котором принимает форму анекдотической нелепицы, объясняет и мотивирует разного

\footnotetext{
30 Там же, с. 236.

31 Там же, с. 237.

32 Там же, с. 249.

33 Там же, с. 240.
} 
рода алогические сдвиги, обнаруживающиеся в его речи и выражающие специфические особенности его мышления ${ }^{34}$. Ср.: «Прекрасный человек Иван Иванович! Какой у него дом в Миргороде!» ${ }^{35}$; «Прекрасный человек Иван Иванович! Его знает и комиссар полтавский!» ${ }^{36}$.

Приведенные высказывания содержат в себе, на первый взгляд, логические ошибки: положение, которое требуется доказать, не вытекает из доводов, приведенных в его подтверждение. Но для рассказчика Иван Иванович прекрасный человек именно потому, что у него особенный дом, вокруг которого «со всех сторон навес на дубовых столбах, под навесом везде скамейки» 37 , и что сам комиссар полтавский его знает. То, что легко принять за логическую ошибку, оказывается перифразой; оценку героя призваны подтвердить не его человеческие качества, как можно было бы ожидать, а замещающие их знаки, каковыми являются дом и репутация. Таков ход мысли рассказчика, отраженной в его алогичных утверждениях.

Мысль рассказчика движется, как правило, не от человека к замещающему его знаку, а от знака к человеку; описание знака и служит характеристикой человека. Подобная логика порождает ассоциации в сравнении: «Иван Иванович несколько боязливого характера. У Ивана Никифоровича, напротив того, шаровары в таких широких складках, что если бы раздуть их, то в них можно бы поместить весь двор с амбарами и строением» ${ }^{38}$. Связь по существу как будто подменяется здесь ходом по смежности ${ }^{39}$, однако ход по смежности и выражает парадоксальным образом связь по существу. От героя, обладающего боязливым характером, рассказчик, что логично для хода его мысли, перескакивает к вещи, представительствующей вместо другого героя и наделенной признаком пространственной смелости: она способна вместить в себе весь двор с амбарами и строением.

Склонность рассказчика к алогичным высказываниям объясняется и известной его родственностью по складу мышления и характеру мировосприятия персонажам, выведенным в повествовании. Их очевидными прототипами выступают простаки и глупцы из анекдотической сказки. Анекдотическим простаком выглядит Иван Никифорович, которого Агафия Федосеевна, хотя

34 См. примеры алогизмов в речи рассказчика в «Повести о том...»: MANN, Ju. V.: Poètika Gogolja. Variacii k teme. Moskva: Coda, 1996, s. 99-110.

35 GOGOL', N. V.: Polnoje sobranije sočinenij: V 14 t. T. II. [Moskva-Leningrad]: AN SSSR, 1937, s. 223.

36 Там же, с. 224.

37 Там же, с. 223.

38 Там же, с. 227.

39 См.: BOČAROV, S. G.: O stile Gogolja. In: Teorija literaturnych stilej: Tipologija stilevogo razvitija Novogo vremeni. Moskva: Nauka, 1976, s. 443. 
и не была ему «ни родственницей, ни свояченицей, ни даже кумой» ${ }^{40}$, ловко схватила за нос «и водила за собою, как собачку» ${ }^{41}$. Убедив Ивана Никифоровича, в результате чего «всё пошло навыворот», не мириться с Иваном Ивановичем, потому что тот его «погубить хочет» ${ }^{42}$, она действует так, как злая жена в анекдотах.

Внушаемость Ивана Никифоровича относится к изображаемой в анекдотической сказке «„пассивной“ глупости», свойственной простаку, но поступки, совершаемые им не только под влиянием Агафии Федосеевны, но и по собственному почину (например, возведение гусиного хлева прямо против соседа), говорят уже об «„активной“ глупости» ${ }^{43}$ и переводят его из разряда простаков в разряд глупцов. Уподобляется анекдотическому глупцу и Иван Иванович, когда, обмирая от страха, подпиливает державшие хлев столбы. Глупость проявляется в его поведении, как это случается в анекдотах, и «...в слишком буквальном понимании вещей...» ${ }^{44}$, заставляющем доказывать, что он не птица, а человек. Активную глупость демонстрирует также старуха, решившая повесить вместе со шпагою, чтобы проветрить, и ружье, не зная, «из чего оно сделано», так как оно не ее, а «панское» ${ }^{45}$.

Иван Иванович с Иваном Никифоровичем, ввязавшись в судебную тяжбу и наотрез отказываясь от примирения, ведут себя как глупцы из анекдотической сказки. Ср.: «Тогда процесс пошел с необыкновенною быстротою, которою обыкновенно так славятся судилища. Бумагу пометили, записали, выставили нумер, вшили, расписались, всё в один и тот же день, и положили в шкаф, где оно лежало, лежало, лежало год, другой, третий...» ${ }^{46}$. Нелепые (учитывая особенности судилища) поступки героев действительно побуждают вспомнить поведение анекдотических глупцов в аналогичных (поражающих своей абсурдностью) ситуациях.

В основе не только поведения, но и рассуждений гоголевских персонажей лежат абсурдные парадоксы. Городничий объясняет Ивану Ивановичу, что принадлежащая тому свинья, как каждый «похитивший в суде казенную бумагу, подвергается, наравне со всяким другим преступлением, уголовному суду» ${ }^{47}$. И не имеет значения, что свинья не человек, а животное: «...закон

40 GOGOL', N. V.: Polnoje sobranije sočinenij: $V 14$ t. T. II. [Moskva-Leningrad]: AN SSSR, 1937, s. 240.

41 Там же.

42 Там же, с. 241.

43 MELETINSKIJ, Je. M.: Istoričeskaja poètika novelly. Moskva: Nauka, 1990, s. 22.

44 Там же, с. 21.

45 GOGOL', N. V.: Polnoje sobranije sočinenij: V 14t. T. II. [Moskva-Leningrad]: AN SSSR, 1937, s. 230.

46 Там же, с. 263.

47 Там же, с. 259. 
говорит: виновный в похищении... прошу вас прислушаться внимательно: виновный! Здесь не означается ни рода, ни пола, ни звания, стало быть и животное может быть виновно» ${ }^{48}$. Нарушая и правила логики, и требования здравого смысла, городничий облекает свое толкование закона, чего заметить, обнаруживая черты анекдотического глупца, не способен, как раз в форму абсурдного парадокса. Множась и накапливаясь, абсурдные парадоксы, как и алогичные высказывания и такого же рода действия, способствуют усилению нагнетаемой в повествовании атмосферы абсурда.

В «Повести о том...» алогизмы используются не просто как комические приемы повествования. В алогичных суждениях и утверждениях проступает отклонение от онтологических норм, когда искажаются представления о законах бытия. Существенна в этом плане стилевая и стилистическая многоликость рассказчика, с одной стороны, сближенного (вплоть до финала) с персонажами и обладающего общей с ними картиной мира, с другой, обнаруживающего способность к смене нарративных масок. Различные формы алогизмов позволяют высветить в процессе повествования аномальное устройство изображаемого мира; резко меняя ракурс повествования, рассказчик раскрывает и обнажает самое онтологию абсурда.

От основного повествования финал, выполняющий функцию эпилога, отделяет зияющий хронологический разрыв: рассказчик сообщает, что «проезжал чрез город Миргород» (точкой отсчета служит время рассказывания) «лет пять» тому назад, а до этого он «двенадцать лет не видал Миргорода», где «жили тогда в трогательной дружбе два единственные человека, два единственные друга», но с тех пор немало уже «вымерло знаменитых людей» ${ }^{49}$. Как изменился за эти годы сам рассказчик, остается за границами рассказываемой истории, но показательно, что рисуемый им безрадостный осенний пейзаж и вид пустой в воскресный день церкви, где почти не было народа, вызывают у него несвойственное ему ранее чувство глубокой и непритворной грусти, заставляя обратить внимание на свечи, которые при «больном дне» были «странно неприятны», на «темные притворы», выглядевшие так «печально», и на «продолговатые окна с круглыми стеклами», которые «обливались дождливыми слезами» 50 .

Неожиданная встреча сначала с Иваном Никифоровичем, постаревшим и поседевшим, но по-прежнему надеющимся на благоприятный для него исход все тянущейся «тяжбы», а затем с Иваном Ивановичем, тоже постаревшим

\footnotetext{
48 Там же, с. 260.

49 Там же, с. $274-275$.

50 Там же, с. 275 .
} 
и поседевшим, но уже после «первых приветствий» уведомляющим о скором решении «дела» ${ }^{51}$, побуждают рассказчика, покидающего Миргород, лишь глубже погрузиться в овладевшее им состояние: «Опять то же поле, местами изрытое, черное, местами зеленеющее, мокрые галки и вороны, однообразный дождь, слезливое без просвету небо. - Скучно на этом свете, господа!» ${ }^{2}$.

Слово скучно оказывается в одном синонимическом ряду со словом тоска, обозначающим в народных представлениях состояние, возникшее в результате демонического воздействия. Такой враждебной человеку силой, отрицательно воздействующей на рассказчика и ввергающей его в не менее болезненное, чем состояние тоски, состояние скуки, и выступает «Повести о том...» вездесущий и всепроникающий абсурд. Именно абсурд, как выясняется, и есть сущность этого света, как будто навсегда утратившего представление о мире как отсутствии вражды и благоустроенном космосе.

\section{Литература:}

BOČAROV, S. G.: O stile Gogolja. In: Teorija literaturnych stilej: Tipologija stilevogo razvitija Novogo vremeni. Moskva: Nauka, 1976.

GOGOL', N. V.: Polnoje sobranije sočinenij: $V{ }_{14} t$. T. II. [Moskva-Leningrad]: AN SSSR, 1937.

MANN, Ju. V.: Poètika Gogolja. Variacii k teme. Moskva: Coda, 1996.

MELETINSKIJ, Je. M.: Istoričeskaja poètika novelly. Moskva: Nauka, 1990.

\section{About the author}

\section{Vladislav Shaevich Krivonos}

Samara State Social and Pedagogical University, Faculty of Filologia, Department of Literature, Samara, Russia vkrivonos@gmail.com

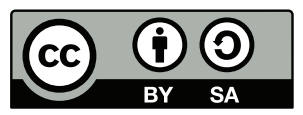

This work can be used in accordance with the Creative Commons BY-SA 4.0 International license terms and conditions (<https://creativecommons.org/licenses/by-sa/4.0/legalcode>). This does not apply to works or elements (such as images or photographs) that are used in the work under a contractual license or exception or limitation to relevant rights.

51 Там же, с. 275-276.

52 Там же, с. 276. 
